\title{
A SOCIOLOGIA NO ENSINO MÉDIO E A DIFÍCIL TAREFA DE MOSTRAR A SUA IMPORTÂNCIA PARA OS ALUNOS
}

\author{
Maria Luzia Silva Mariano \\ Universidade Estadual de Londrina - UEL, Londrina - PR. E-mail: malumariano@yahoo.com.b
}

\section{RESUMO}

O presente trabalho apresenta reflexões sobre a posição que a Sociologia ocupa no currículo escolar do ensino médio e a importância que os alunos atribuem à essa disciplina durante as aulas. As reflexões foram feitas com base nas observações sistemáticas feitas nas aulas de Sociologia de duas escolas públicas em uma cidade no sul do estado de Minas Gerais durante a participação como bolsista do Pibid do curso de Ciências Sociais. O objetivo é refletir sobre as dificuldades encontradas pelos professores dessa área em fazer com que seus alunos se interessem pela disciplina. Ao que parece, para os alunos uma disciplina que não tem tradição na sua grade curricular, como a Sociologia, não merece a sua atenção e emprenho durante as aulas. Por essa razão é que aulas que fogem do esquema convencional e projetos como o Pibid se mostram importantes no processo de aprendizado desses alunos.

Palavras-chave: Sociologia, Ensino, Disciplina, Aulas, Alunos.

\section{SOCIOLOGY IN HIGH SCHOOL AND A HARD TASK TO SHOW THEIR IMPORTANCE FOR STUDENTS}

\begin{abstract}
This paper presents reflections on the position that sociology occupies in the school curriculum of secondary education and the importance that students attach to this discipline during lessons. The reflections were based on systematic observations in the classroom of Sociology of two public schools in a city in the southern state of Minas Gerais during participation as a fellow of the Pibid Social Sciences course. The aim is to reflect on the difficulties faced by teachers in this area make their students are interested in the discipline. Apparently, for students a discipline that has no tradition in their curriculum, such as Sociology, does not deserve your attention and human effort during class. For this reason is that classes fleeing the conventional scheme and projects like Pibid show themselves important in the learning process of these students.
\end{abstract}

Keywords: Sociology, Education, Discipline, Classes, Students. 


\section{A SOCIOLOGIA E A SALA DE AULA}

Abolidas do currículo do ensino médio brasileiro desde 1971, por imposição do regime militar que governou o país entre 1964 e 1985, as disciplinas Filosofia e Sociologia voltaram a integrar o quadro de disciplinas ofertadas nas escolas como obrigatórias a partir de 2009. A Lei no 11.684 de 02 de junho de 2008 (BRASIL. PRESIDÊNCIA DA REPÚBLICA, 2008) tornou essas duas disciplinas obrigatórias nas escolas de ensino médio, públicas e privadas de todo o país, tendo as escolas, a partir de 2009, três anos para se adaptar e ministrá-las plenamente. Porém, até a Lei no 11.684/2008 ser sancionada, a Sociologia esteve presente e foi retirada por diversas vezes da grade curricular do ensino médio brasileiro.

Considerando o caminho percorrido pela Sociologia, é possível identificar consequências negativas para sua afirmação como matéria importante e que precisa chegar ao conhecimento dos estudantes, assim como a Matemática, a História ou a Língua Portuguesa. Essa instabilidade da disciplina no currículo do Ensino Médio impediu que a disciplina se tornasse um conteúdo tradicional no sistema de ensino das escolas, ficando prejudicado o desenvolvimento de materiais didáticos específicos para o desenvolvimento dos conteúdos pertinentes à disciplina em sala de aula. Também é possível perceber a falta de incentivo no que diz respeito à pesquisa e à formação do professor para essa área de atuação. (CARVALHO, 2004)

Em decorrência do processo de entrada e saída da Sociologia do currículo obrigatório, alguns problemas se tornaram evidentes: a falta de material didático apropriado para lecionar a disciplina, os parâmetros curriculares específicos que a regulamentassem e servissem de orientação para os professores, a formação de profissionais licenciados em Ciências Sociais e principalmente, como mostrar aos alunos que a Sociologia é fundamental para a sua formação moral e crítica. Nas palavras de Florestan Fernandes (1985, p. 95), “O ensino secundário é formativo por excelência; êle não deve visar a acumulação enciclopédica de conhecimentos, mas a formação do espírito dos que os recebem."

Há evidente necessidade de extirpar dos alunos a noção de que os conhecimentos necessários a se ter domínio ao sair do Ensino Médio são apenas os que apresentam aparentemente maior praticidade, como a Matemática ou a Língua Portuguesa, por exemplo. Sendo o Ensino Médio a etapa final da educação básica, ele deve apresentar elementos que suscitem nos alunos o desenvolvimento da consciência crítica de cidadania política e social, elementos 
indispensáveis à formação humana de todo cidadão, fazendo com que os alunos não se mantenham presos somente aos conhecimentos teóricos que aprendem durante o período escolar. (CARVALHO, 2004).

Sendo assim, o objetivo do presente trabalho é refletir sobre as dificuldades encontradas pelos professores durante as aulas de Sociologia em fazer com que seus alunos se interessem pela matéria e pelo conteúdo que a ela se faz pertinente a partir do relato de uma das experiências pedagógicas positivas que o Pibid (Projeto de Incentivo de Bolsa de Iniciação à Docência) do curso de Ciências Sociais de uma universidade do sul do estado de Minas Gerais apresentou. As aulas que fogem do sistema convencional (passar matéria no quadro, esperar que os alunos a copiem e explicar) se mostraram fortes aliadas nesse processo de ensino-aprendizagem, pois são mais dinâmicas e possibilitam maior interação entre os alunos e o professor, o que desperta o interesse e atenção desses estudantes.

\section{METODOLOGIA}

As reflexões aqui contidas foram feitas a partir de observações sistemáticas ${ }^{1}$, em dezoito turmas diferentes do ensino médio de duas escolas públicas em uma

\footnotetext{
${ }^{1}$ As observações foram registradas em diários de campo
}

cidade no sul do estado de Minas Gerais. As observações faziam parte de uma das atividades semestrais do Pibid do curso de Ciências Sociais da universidade federal local. Dessa forma, os alunos bolsistas tinham livre acesso às escolas parceiras para fazer as observações e também deveriam desenvolver atividades com os alunos das escolas que envolvessem o ensino de Sociologia e também a prática docente.

Sendo assim, a partir das observações sistemáticas, foi identificado um alto índice de indisciplina nas aulas de Sociologia, sendo possível admitir que por não ser a Sociologia uma disciplina tradicional, que esteve presente nos currículos de ensino "desde sempre", como a Língua Portuguesa ou a Matemática, seja difícil para os alunos conceberem sua importância, o que obriga o professor por diversas vezes a fugir do esquema tradicional de aula para tentar chamar a atenção dos alunos fazendo com que eles se interessem pelo conteúdo e entendam a sua importância.

As atividades realizadas por projetos como o Pibid se mostram eficientes no processo de chamar a atenção dos alunos durante as aulas e conseguir a sua participação nas mesmas. Como alternativa para fugir das aulas que são de praxe, podem ser consideradas atividades como palestras, cinema na universidade, debates ou atividades com dinâmicas, pois tais 
atividades tiram os alunos da sua rotina escolar que é maçante, trabalhando com o conteúdo pertinente à disciplina e à atualidade.

As intervenções foram realizadas nas duas escolas parceiras em datas diferentes, contando com a participação de todas as turmas do ensino médio das duas escolas. 0 planejamento das atividades sempre foi baseado nos documentos de indicação governamental sobre os temas e conteúdos que os alunos devem dominar ao final dessa etapa do ensino básico.

\section{RESULTADOS E DISCUSSÃO}

Documentos como o PCNEM (Parâmetros Curriculares Nacionais para o Ensino Médio), CBC (Conteúdo Básico Comum) ou as OCEM-Sociologia (Orientações Curriculares para o Ensino Médio Conhecimentos de Sociologia), trazem direcionamentos de temas e conteúdos que devem ser trabalhados durante as aulas. De acordo com as OCEM-Sociologia, o ensino dessa disciplina na educação básica deve se pautar em dois princípios básicos: o estranhamento, que é o ato de se espantar, se admirar diante de algo ou alguém, ocasionando consequentemente 0 questionamento sobre o porquê dos fatos em questão; e a desnaturalização, que consiste em mostrar que os fenômenos sociais são apenas de origem humana, que não é possível explicar a sociedade com base em argumentos naturalizadores.

Guimarães e Moraes (2010) discorrem a respeito dessa temática, evidenciando formas de impulsionar e aprimorar o trabalho do professor de Sociologia, que não se mostra como uma tarefa fácil atualmente. A partir das observações e dos relatos dos professores foi possível perceber que os alunos não se interessam pela matéria pois não conseguem entender a aplicabilidade da mesma no seu cotidiano e não entendem a importância para a sua formação crítica e cidadã. Os alunos quando questionados sobre a falta de interesse, relataram que a baixa carga horária da disciplina e a exposição extremamente teórica dos conceitos diminui o seu interesse durante as aulas.

Os autores supracitados apontam algumas ferramentas que eles consideram eficazes para despertar nos estudantes o interesse pela disciplina, que voltou há tão pouco tempo ao currículo do ensino médio e quase não é valorizada pelas instituições de ensino. Alguns exemplos dessas ferramentas são as aulas expositivas em conjunto com outros recursos didáticos, as aulas musicais, as visitas dirigidas, ou mesmo o debate dos temas a partir de palestras ou exibição de filmes que sejam pertinentes à temática à ser trabalhada e possibilitem uma análise crítica posterior. 
Sendo assim, o relato da experiência positiva da atividade escolhida figura como uma alternativa de mudança para as aulas consideradas maçantes pelos alunos. Tratase do "Dia da Sociologia", um projeto realizado com os alunos das escolas parceiras do Pibid com o objetivo de proporcionar atividades dinâmicas relacionadas aos conteúdos de Sociologia. Esperava-se que dessa maneira os alunos se interessassem pelos conteúdos e direcionassem a atenção necessária para que pudessem adquirir os conhecimentos que estavam sendo transmitidos e assemelhassem a sua importância.

Inicialmente os alunos das duas escolas parceiras deveriam ir até a universidade para que as atividades fossem executadas lá durante o período em que os alunos deveriam estar na escola. A diretoria da Escola $P 1^{2}$ pediu aos alunos que fossem andando, juntamente com os professores e tudo correu bem nesse quesito. No entanto, a Escola P2 não conseguiu que a prefeitura da cidade ou que a universidade disponibilizasse o ônibus para o transporte dos alunos, e devido à localização da escola, era inviável que os alunos fossem a pé até a universidade. Assim, os bolsistas do Pibid se deslocaram até a escola e desenvolveram na escola P2 as mesmas atividades que foram

\footnotetext{
${ }^{2}$ As escolas serão mencionadas com escola P1 e P2 para sua diferenciação e para que os nomes das mesmas não sejam divulgados.
}

realizadas na universidade com os alunos da escola P1.

As atividades foram iniciadas com uma palestra ministrada por um professor convidado sobre 'Gênero e Sexualidade'. Após a fala do professor foi realizado uma discussão sobre o tema exposto e o esclarecimento de possíveis dúvidas dos alunos. Ao fim do debate foi realizada uma pequena pausa e com a volta das atividades os alunos foram divididos em quatro grupos para que pudesse ser realizadas uma dinâmica sobre padrões de beleza, que teve por objetivo desenvolver a consciência dos jovens com relação ao seu corpo; perceber o papel dos meios de comunicação ao influenciar na formação da auto-imagem e como esta afeta a conduta das pessoas, além de introduzir um conceito mais amplo de beleza.

Para finalizar, foi exibido para os grupos o curta-metragem 'Acorda, Raimundo... Acorda!!!', e a discussão sobre os principais pontos do filme, que se relaciona diretamente ao tema do projeto: gênero e sexualidade. O curta mostra a inversão de papéis entre o homem e a mulher em uma família tradicional, em que a mulher sai para trabalhar fora e cuida do sustento da casa enquanto o homem fica em casa cuidando dos filhos e das tarefas domésticas. No final do curta, tudo não passou de um pesadelo muito estranho de 
Raimundo, o protagonista, teve durante a noite.

A receptividade dos alunos com as atividades foi impressionante. A grande maioria ouviu atentamente a fala do professor durante a palestra e participou com perguntas ou considerações. Eles também mostraram interesse no desenvolvimento da dinâmica, pois a grande maioria apresentou conceitos formados sobre os padrões de beleza, mas conseguiu fazer a desconstrução desses padrões ao longo da atividade. Por fim, os alunos acharam importante refletir sobre a troca de papéis apresentada no curta metragem e conseguiram refletir sobre as estruturas familiares que têm se configurado na sociedade atual e como essa estrutura se dava antigamente. Foi evidente o quanto essas atividades apresentam um índice de disciplina maior que durante as aulas convencionais.

\section{CONSIDERAÇÕES FINAIS}

Várias são as questões que podem ser consideradas como as responsáveis pela indisciplina dos alunos, não sendo possível restringir a explicação de tal fenômeno a apenas uma característica. Contudo, neste trabalho se pretendeu explanar sobre o fato de como o conteúdo a ser trabalhado é apresentado aos alunos e como técnicas de ensino, como a exibição de curta-metragens, palestras e debates ou a utilização de recursos multimídia, podem se mostrar mais atrativas aos alunos estimulando a sua participação e atenção durante as aulas.

François Dubet (1997, p. 223) afirma que a grande dificuldade encontrada pelo professor é fazer com que o aluno trabalhe, já que eles se aborrecem com as orientações, não escutam e não trabalham espontaneamente. $\mathrm{O}$ autor diz que em uma aula com duração de uma hora, só se aproveitam vinte minutos, os outros quarenta minutos são utilizados para colocar a sala em ordem e para passar orientações, pois "[...] os alunos não estão "naturalmente" dispostos a fazer o papel de aluno".

As atividades, no que diz respeito à Sociologia, também precisam ser previamente preparadas para que se possa otimizar o tempo da aula, já que com a carga horária reduzida, a demora na organização da sala e no início das atividades prejudica ainda mais, pois é um conteúdo extenso a ser trabalhado em um tempo mínimo. Perde-se na qualidade do ensino, sendo este outro fator que faz com que os alunos não deem importância para a matéria.

Alguns alunos, quando questionados sobre a falta de interesse pela Sociologia dizem: "Ah, é uma aula por semana só, não dá pra entender nada mesmo, por isso não me importo". Contribui para tal situação e também para a maior incidência de 
indisciplina, nas aulas de Sociologia, a importância que a própria escola parece dar à matéria. Nas escolas observadas, sempre que era necessário dar algum aviso, quando acontece algum evento na escola, quando as provas enviadas pelo governo são aplicados, a aula utilizada é a de Sociologia, algumas vezes até mesmo sem o aviso prévio aos professores regentes. Esses fatores contribuem para a manutenção e disseminação do pensamento de que algumas matérias são mais importantes que as outras.

O caminho a ser percorrido para que a matéria mostre sua importância ainda é longo. É preciso trabalhar na conscientização desses alunos desde o início de sua trajetória escolar, deixando de lado conceitos préestabelecidos sobre a maior ou menor relevância dos conteúdos. Fazer com que os alunos se interessem pela Sociologia, uma matéria que para eles se apresenta como extremamente teórica não é fácil, por isso o Pibid contribui na formação do licenciando, trazendo novos métodos para se trabalhar um mesmo conteúdo, tornando a matéria mais dinâmica e, portanto, mais atrativa aos alunos.

\section{REFERÊNCIAS}

BRASIL. Presidência da República. Lei no. 11.684 de 02 de junho de 2008. Estabelece as diretrizes e bases da educação nacional, para incluir a Filosofia e a Sociologia como disciplinas obrigatórias nos currículos do ensino médio. Disponível em: <http://www.planalto.gov.br/ccivil_03/_Ato2 007-2010/2008/Lei/L11684.htm>. Acesso em: 20 jan. 13.

CARVALHO, L. M. G. (Org.). Sociologia e ensino em debate: experiências e discussão de sociologia no ensino médio. Ijuí: Unijuí, 2004. 392 p.

DUBET, F. Quando o sociólogo quer saber o que é ser professor. Revista Brasileira de Educação, Rio de Janeiro, n.5-6, 1997. p. 22231.

FERNANDES, F. O ensino de sociologia na escola secundária brasileira. In: Primeiro dossiê de ciências Sociais. São Paulo: CEUPES-USP/CACS - PUC, 1985. p. 89-106.

GUIMARÃES, E. F.; MORAES, A. C. Metodologia de Ensino de Ciências Sociais: relendo as OCEM-Sociologia. In: MORAES, A. C. (Org.). Sociologia: ensino médio. Brasília: Ministério da Educação, 2010. v. 15, p. 45-62.

Recebido para publicação em 19/08/2014

Revisado em 02/09/2014

Aceito em 06/09/2014 